\title{
Prediction Markets: Do They Predict the Polls or the Election Results? The Case of the Israeli Elections in April 2019
}

\author{
Rachel Calipha* and Itzhak Venezia ${ }^{\dagger}$
}

\begin{abstract}
Prediction markets have been found to provide relatively accurate and inexpensive means for forecasting various events including elections results. However, since in most political elections, there exist public polls that predict the results as well as betting houses that publish odds on the various candidates and since voters obtain information from these sources, the marginal contribution of prediction markets is uncertain and needs to be assessed empirically. In this chapter, we investigate the correlations between poll results and prediction markets results throughout the election campaign in Israel prior to the April 2019 elections and compare their accuracy. We show that although correlated and influenced by the polls, prediction markets have some value. Given their minimal costs of operation, such markets are worthwhile.
\end{abstract}

Keywords: Prediction markets, political stock markets forecasting, polls, Israeli elections

*The Academic College of Tel Aviv-Yaffo, Israel; rachel.calipha@gmail.com.

${ }^{\dagger}$ The Academic College of Tel Aviv-Yaffo, Israel; Itzhakvenezia@gmail.com. 


\section{Introduction}

Prediction markets have been suggested as an accurate and inexpensive method for predicting various unknowns. The premise of such markets is that they would be more accurate than polls or than asking people for their opinions because in such markets, participants have financial stakes at being right. The respondents to polls on the other hand do not stand to lose or gain anything from being wrong or right (except maybe the pride) and hence will be less motivated to think carefully and provide honest opinions. ${ }^{1}$ It is also well known that in previous elections in Israel, some respondents to polls have deliberately and strategically misrepresented their opinions. $^{2}$

Whereas participants in prediction markets have more incentives to perform well than participants in polls, they usually are not a representative sample of likely voters. ${ }^{3}$ Thus, the balance of advantages and disadvantages of one method vs. the other is not a priori certain. The question of which method is superior, or whether it is optimal to use the combination of both methods, thus remains to be resolved empirically. Thus far, the jury is hung. ${ }^{4}$ In their study of several major polling organizations, Berg et al. (2008), found that prediction markets outperformed polls in 9 of 15 cases. They report an average poll error of $1.91 \%$ and lower prediction market

\footnotetext{
${ }^{1}$ However, Hvide et al. (2019) claim that self-reporting (a method similar to polls) are often more advantageous than experiments with small stakes (a method similar to prediction markets).

${ }^{2}$ Schneider (2019) reports in Globes (an important Israeli newspaper) that senior advisers to the Likud party told the media how down the stretch in the campaigns of 2013 and 2015 orders were given to supply the pollsters with false answers in order to arouse complacency in the opponents' side. This was given as a possible explanation why in all the elections of the last decade polls down estimated the votes for the Likud. Polls preceding the September 2019 elections became more aware of this problem than before the April 2019, which possibly explains their better performance in the latter elections which took place September 17, 2019.

${ }^{3}$ According to Berg et al. (2008), in the Iowa Election Markets the participants were over whelmingly male, well educated, had high income and young.

${ }^{4}$ The division of opinion seems to be correlated with the main field of the researchers. As suggested by Dana et al. (2019), psychologists typically prefer forecasts based on self-reports, whereas economists are much more likely to base them on behavior (prediction markets).
} 
errors of $1.49 \%$ or $1.58 \%$ (according to the two measures of accuracy they used), thus indicating an edge for the prediction markets. ${ }^{5}$ Arrow et al. (2008, p. 878) were even stronger in favor of prediction markets and called "to clear away regulatory barriers that were never intended to inhibit socially productive innovation [prediction markets]."

On the other hand, Atanasov et al. (2016, p. 1) suggest that "prediction polls with proper scoring feedback, collaboration features, and statistical aggregation are an attractive alternative to prediction markets for distilling the wisdom of crowds." Dana et al. (2019) found evidence that markets outperform self-reports if the latter are just averaged. However, the reverse is true if the self-reports team-prediction polls when the self-reports' forecasts were statistically aggregated using temporal decay, differential weighting based on past performance, and recalibration. The combination of both methods these authors suggest is even better.

In the Israeli elections of April 2019, prediction markets were held side by side to public polls. The accuracy of these two methods is compared in this chapter, but this is not the main question we ask. Given that polls are a standard fixture of elections and that they are not likely to be replaced, the question we pose is whether the prediction markets provide any predictive power above the polls. Throughout the elections campaign, participants in the prediction markets get a great amount of information from polls published in the media. This strikes another puzzle: How well the markets would have performed in the absence of polls? And why would participants in such markets believe that they can outperform the polls; after all, the polls are conducted by professional statisticians who invest in their design and execution considerable amounts of money and have access to superior information sources than most participants in the prediction markets. The pollsters in Israel are known to be ethical

\footnotetext{
${ }^{5}$ These results however are not overwhelmingly in favor of prediction markets. Assuming that the results in the various cases are independent, we calculated that the null hypothesis that the two methods are equally good cannot be rejected by a non-parametric test, since under these assumptions, the probability that markets outperform polls in 9 or more cases out of 15 is $15 \%$. We could not calculate the significance of the difference between the percentage errors of the two methods since the authors provided only averages but not standard deviations.
} 
and show no bias in favor of any politician (or party) and are highly motivated to perform well. The three largest TV stations in Israel, each employing a different polling firm, fiercely compete on their accuracy. Being more accurate is important to the TV station that employs the polling firm, since it provides the station with prestige and improves their ratings; the pollsters' reputation and hence, their future jobs potential depend on accuracy as well. ${ }^{6}$ The pollsters are therefore not less motivated to perform well than the participants in prediction markets.

Proponents of prediction markets often cite the potential of each of their participants to learn from the behavior of the other participants and to aggregate efficiently information from all sources. However, the participants in the markets usually have access to sources of information inferior to those of the pollsters and hence the rational participant does not have any reason to believe that either himself/herself or his/her competitors know any better than the polls or is able to process information better than the pollsters. Besides strategies of outwitting the other participants in the market, overconfidence bias, or some other behavioral biases, it is hard to imagine any reason why participants do not assume the polls to be their best estimates, but in such cases prices might not be efficient predictors of the voting results. Participants may not only rationally herd but also in this case the market might become inefficient (see, e.g., Bickhchandani et al., 1992; Froot et al., 1992). Participants may believe that pollsters just use simple averages of their findings in their forecasts, in which case, their forecasts would be inferior to those obtained by markets. Whereas the aforementioned generally is true for most days prior to the elections, in Israel, prediction markets have an advantage over polls in the last three days prior to elections day. By law, the media are forbidden to publish the results of polls that have been taken in these days. The media can publish the results of polls taken on elections day and on the three days before it, only after the closing of the ballot stations on elections day. Prediction

\footnotetext{
${ }^{6}$ Mina Tsemach, the chief statistician of a veteran and respectable polling firm resigned following the poor performance of her firm's predictions in the elections of April 2019. Her partner attributes their failings to deliberate false reports of Likud voters (Shalita, 2019).
} 
markets can provide information in the three days prior to the elections, which public polls are prohibited from providing.

The chapter is constructed as follows. In Section 2, we explain how the prediction markets was constructed and operated. We also provide some institutional information about the Israeli elections process. In Section 3, we present tests of the efficiency of the prediction markets. In Section 4, we compare the accuracy of the prediction markets vs. the polls and in Section 5, we analyze the correlation between them. Concluding remarks are provided in the Section 6 .

\section{Methodology, Participants and Data}

\subsection{Subjects}

Around $129 \mathrm{MBA}$ and BA students from Bar Ilan University and 93 from the Academic College of Tel Aviv-Yaffo registered for the market (90 women and 132 men) with an average age of about 30 years. Only about 100 of those registered traded more than once.

\subsection{The Market and Its Operation}

Each participant received 60 ILS to participate in the market that operated continuously between February 18, 2019 to April 9, 2019 on a platform provided by the consulting firm "Darebiz." 7 At each point, the participants could either buy or short-sell futures of each of the 13 largest parties that ran for the Israeli parliament in the elections to be held on April 9, 2019 (the parties included in our market were the 13 largest ones: KacholLavan, Likud, Ha'avoda, YahadutHaTorah, Hadash-Taal, HayminHachadash, IhudHayamin, Meretz, Shas, Zehut, Kulanu, Israel Beytenu and Raam-Balad). The underlying asset in this market was the number of seats the party will receive in the "Knesset" (the Israeli parliament) out of the 120 seats available, and each seat is worth 1 ILS. The elections date served as the expiration date of the futures. At each point the trading participants could see on the screen of the trading platform the previous sell

\footnotetext{
${ }^{7}$ This firm also paid the subjects for their participation and their profits from their trading.
} 
and buy prices, the changes from the previous trades and the result of the latest published poll. The trader could submit a buy/sell order and Darebiz's (private) algorithm calculated an equilibrium price. In accuracy comparisons between the predictions of our market and those of the polls, we used the poll results provided by "Darebiz," which were based on the latest results published each evening by one of the three largest TV stations operating in Israel who offered predictions every day throughout the campaign. We defined the predictions of our market, on each day of the elections campaign, to be the average prices paid for the futures of the party during the day. The profits/losses of each participant from each future held on expiration were the difference between the prices of the futures and the official number of seats the party obtained in the elections. ${ }^{8}$

\section{Tests of Market Efficiency}

Although it is not our main goal in this chapter, we found it interesting to examine whether our prediction market is efficient. ${ }^{9}$ We chose to only test for correlation between returns (weak form efficiency) and decided that further tests (semi strong or strong efficiency tests) would be needed only if no correlation would be detected. Since correlation was detected, no further tests were needed. A finding of inefficiency would indicate a flaw in this market as past returns do not incorporate all the information. If such a market were to beat the polls this would constitute as an even worse sign for the polls, since it would imply that an efficient market could trample them even stronger.

We first ran autocorrelation tests for the returns of each party separately. We ran for each of the 13 parties a regression of the form:

$$
R_{t}=a+b R_{t-1}
$$

\footnotetext{
${ }^{8}$ The official results of the elections were declared only about a month after the elections because of the complex system of counting the votes and appeals of the results raised by some parties alleging foul play or mistakes in the counting.

${ }^{9}$ In this section, efficiency is defined in the classical weak form of efficiency in finance (i.e., prices should reflect all information about previous returns). One could define, alternatively, the market as being efficient if it provides better estimates than its alternative (polls) at lower costs.
} 
where the returns on the futures on day $t$ are defined by:

$$
R_{t}=\left(P_{t}-P_{t-1}\right) / P_{t-1}
$$

and $P_{t}$ denotes the average price of the future during day $t .^{10}$

The results of running these regressions are provided in Table 1.

We observe from Table 1 that for all parties the returns are negatively correlated indicating inefficiency. The negative correlation was not statistically significant for all parties. However, a non-parametric test would reject the null hypothesis that the market is efficient. Under this hypothesis there is a $50 \%$ chance that the slope of the regression is negative and hence, the chance that for all parties the slope of the regression is negative is $(1 / 2)^{13}$ a probability well below the critical value of 0.001 needed to reject the null hypothesis. The returns on the two largest parties turned out significantly negative, indicating inefficiency even for the more active parties. Whereas the autocorrelation between returns turned out significant, its economic significance is unclear and the possibility of arbitrage to take advantage of this inefficiency was not realistic. The $R^{2^{\prime}}$ s were also small, indicating that the association between successive returns is quite

Table 1: The estimated parameters of Eq. (1)

\begin{tabular}{|c|c|c|c|c|c|c|c|}
\hline Parameter & Hadash 1 & Ha'avoda & $\begin{array}{c}\text { Ihud } \\
\text { Hayamin }\end{array}$ & $\begin{array}{c}\text { Israel } \\
\text { beytenu }\end{array}$ & $\begin{array}{l}\text { Kachol } \\
\text { Lavan }\end{array}$ & Kulanu & Likud \\
\hline$B$ & -0.09 & -0.16 & $-0.28^{*}$ & $0.14^{* * *}$ & $-0.54^{* * *}$ & $-0.26^{*}$ & $-0.32^{* * *}$ \\
\hline$N$ & 42 & 49 & 42 & 47 & 42 & 49 & 43 \\
\hline$R^{2}$ & 0.01 & 0.00 & 0.08 & 0.18 & 0.29 & 0.07 & 0.18 \\
\hline Parameter & Meretz & $\begin{array}{l}\text { Ra'am } \\
\text { Balac }\end{array}$ & Shas & \multicolumn{2}{|c|}{$\begin{array}{c}\text { Haymin } \\
\text { Hacha } \\
\text { dash }\end{array}$} & $\begin{array}{l}\text { Yaha- } \\
\text { dutHa } \\
\text { Torah }\end{array}$ & Zehut \\
\hline$B$ & 0.06 & -0.15 & -0.07 & -0.08 & & 0.03 & $-0.05^{* * *}$ \\
\hline$N$ & 49 & 42 & 49 & 49 & & 49 & 42 \\
\hline$R^{2}$ & 0.00 & 0.00 & 0.01 & 0.01 & & 0.00 & 0.38 \\
\hline
\end{tabular}

Note: ${ }^{*} p<0.1,{ }^{* *} p<0.05$ and ${ }^{* * *} p<0.01$.

\footnotetext{
${ }^{10}$ Qualitatively similar results to all our tests were obtained also when we used end of day prices.
} 
scattered. When all parties were considered in one panel data regression, we also obtained statistically significant negative temporal correlation between the returns. All the aforementioned findings taken together imply that technically prices in the market did not reflect all information.

\section{The Accuracy of the Prediction Markets vs. the Polls}

In column 1 of Table 2, we present the latest prices of the predictions market prior to the elections; in column 2 the latest predictions of the polls (which by law were taken three days before the elections) and in column 3 the official results of the elections are listed. The raw results are presented in Panel A and the precision measures in Panel B. The predictions market fared better than the polls on average. From Panel B we observe that the average absolute errors and the mean squared errors of the predictions market are 2.46 and 10.36, respectively, compared with 3.00 and 16.23 of the polls. The standard deviations of the prediction market were also lower. The average errors of the prediction market turned out positive, as the prices of this market were not calibrated to sum up to 120 .

Since the last polls were taken three days before the elections, whereas the market continued trading until the last day, it seems that we imposed a handicap on the polls compared to the market. We therefore also compared the accuracy of the latest polls to that of the market prices determined on that day (in column 6 of Panel A). We observe by comparisons of columns 2 and 6 of Panel B of Table 2, that the market prices three days prior to the elections also provided more accurate predictions on average than the polls (for instance an average absolute error of 2.65 for the market compared to 3 for the polls).

The extent to which the aforementioned differences in accuracy are consequential is a matter of opinion and of the political reality. In this regard, we note that the differences in favor of the prediction market are higher for the bigger parties (about 4 seats difference for the largest party and 1.3 for the second largest). Such differences are 
Table 2: The predictions of the market and the polls and comparisons of their accuracy

\begin{tabular}{|c|c|c|c|c|c|c|}
\hline $\begin{array}{l}\text { Party } \\
\text { Name }\end{array}$ & $\begin{array}{c}\text { Last Trading } \\
\text { Price }\end{array}$ & $\begin{array}{l}\text { Last Poll } \\
\text { Predictions }\end{array}$ & $\begin{array}{l}\text { Official } \\
\text { Results }\end{array}$ & $\begin{array}{c}\text { Errors, Predictions } \\
\text { Market }\end{array}$ & $\begin{array}{l}\text { Errors, } \\
\text { Polls }\end{array}$ & $\begin{array}{c}\text { Trading Prices } 3 \\
\text { Days before the } \\
\text { Elections }\end{array}$ \\
\hline \multicolumn{7}{|c|}{ Panel A: Summary Statistics } \\
\hline KacholLavan & 32.015 & 28 & 35 & -2.99 & -7 & 33.30 \\
\hline Likud & 29.335 & 28 & 35 & -5.67 & -7 & 29.67 \\
\hline Hadash-Taal & 6.55 & 6 & 6 & 0.55 & 0 & 6.91 \\
\hline HayminHachadash & 6.395 & 6 & 0 & 6.39 & 6 & 6.08 \\
\hline IhudHayamin & 6 & 6 & 5 & 1 & 1 & 6.41 \\
\hline Meretz & 5.525 & 5 & 4 & 1.53 & 1 & 5.63 \\
\hline Shas & 5.495 & 5 & 8 & -2.51 & -3 & 5.25 \\
\hline Zehut & 5.1 & 6 & 0 & 5.1 & 6 & 5.40 \\
\hline \multicolumn{7}{|c|}{ Panel B: Precision Measures } \\
\hline Average Absolute Error & 2.46 & 3 & 2.65 & & & \\
\hline Mean squared Error & 10.36 & 16.23 & 10.64 & & & \\
\hline Std. Dev & 3.327 & 4.192 & 3.37 & & & \\
\hline Average Error & 0.384 & -0.077 & 0.42 & & & \\
\hline
\end{tabular}


quite material in the Israeli parliament and could mean the difference between deadlock or a big win (or loss) for one of the leading parties.

\section{The Correlation between the Prediction Markets Prices and the Polls}

The participants of the prediction markets and the polls were predicting the same unknown, and if they used similar sources of information for their predictions this would suffice to create a correlation between them. This correlation would be magnified if market participants used the polls in their predictions. Since the market participants observe the polls but not vice versa, it is plausible that the polls would affect the markets, and that causality, if any, would run only in one direction.

To what extent do market participants employ information other than the polls? Some indication can be glimpsed from intraday price variation in the prediction markets. During the day, no new polls results were provided by the TV stations and hence, variation of prices during the days could roughly imply that market participants received new information beside polls information. ${ }^{11}$ The lower the intraday price variation, the lower, we would suspect, the non-polls information the market participants received. A trend of the intraday standard deviation over time would then indicate whether the relative influence of the polls diminished or increased over time.

To examine this trend, we regressed the intraday daily standard deviation on time. A negative slope of this regression would indicate that these standard deviations diminished as the time to elections neared. In Table 3, we present the average intraday standard deviation of prices for each of the parties and their evolutions over time, i.e., the slopes of the aforementioned regressions. We observe in this table that for all parties the standard deviations of intraday

\footnotetext{
${ }^{11}$ Intraday variation could result from other reasons. However, if during the day there is no one uniform source of information for all market participants (such as polls) and each participant receives information from his/her source, this would give rise to an increased intraday variation.
} 
Table 3: Average daily standard deviation of prices and their evolutions over time

\begin{tabular}{lcc}
\hline Party & $\begin{array}{c}\text { Change in Std. Dev. as } \\
\text { the Elections were } \\
\text { Nearing }\end{array}$ & $\begin{array}{c}\text { Average Daily } \\
\text { Standard Deviation } \\
\text { of Prices }\end{array}$ \\
\hline Hadash-Taal & -0.002 & 0.198 \\
Havoda & -0.016 & 0.273 \\
IhudHayamin & -0.005 & 0.092 \\
Israel Beytenu & -0.022 & 0.348 \\
KacholLavan & -0.012 & 0.501 \\
Kulanu & -0.006 & 0.252 \\
Likud & -0.003 & 0.507 \\
Meretz & -0.009 & 0.220 \\
Raam-Balad & -0.007 & 0.169 \\
Shas & -0.010 & 0.179 \\
HayminHachadash & -0.014 & 0.275 \\
YehadutHaTorah & -0.013 & 0.257 \\
Zehut & -0.006 & 0.218 \\
\hline
\end{tabular}

prices diminished over time. ${ }^{12}$ Also, a panel random effect regression of standard deviation as a function of time provided a significant negative correlation of $-0.01(p<0.01, N=626)$. These results are consistent with the hypothesis that as time to elections neared, the effect of the information unrelated to polls that the market participants received diminished.

In what follows, we analyze the correlation between the market prices and the polls results. We ran quite a few regressions to study these correlations. However, because the results of all different regressions point to similar conclusions, we present the results of just one of them. ${ }^{13}$ In this example, we ran a panel data regression with random effect where the average price is the dependent variable, and the independent variables are the lagged average price and the polls forecast. The coefficients of these variables (0.78 and 0.22 ,

\footnotetext{
${ }^{12}$ We can invoke an argument, same as in Table 1 , that the fact that all slopes are negative implies a significant negative relationship between the variables even if each slope individually is not significantly negative.

${ }^{13}$ The results of the other regressions could be obtained from the authors upon demand.
} 
respectively) were positive and statistically significant $(p<0.01$, $N=607)$.

The correlation between the polls and market prices is striking, but not surprising since the market participants could observe (and probably did) the results of the polls. We thus also explored whether there was a Granger causality between these variables. We ran such causality tests for each party separately and for the whole sample. For the whole sample we tested the null hypotheses that all lags of polls do not cause prices, and vice versa. The null hypotheses were rejected by a Chi squared test $\left(\mathrm{Chi}^{2}=26.63\right.$ for polls affecting prices and 21.69 for causality in the other direction).

Whereas the hypothesis that polls affect prices is plausible, the reverse is not, and it may be due to using too many lags by the program and the only thin variation of the variables over time.

When running the tests for each party separately, the results, presented in Table 4, were slightly different. We observe from Table 4 that when studied separately, there is Granger causality between the polls and market prices for six parties, which agrees with our intuition

Table 4: $\quad F$ Values for Granger causality tests

\begin{tabular}{llll}
\hline & & $\begin{array}{c}F \text { Values for } \\
\text { Testing That } \\
\text { Polls Granger } \\
\text { Cause Prices }\end{array}$ & $\begin{array}{c}F \text { Values for } \\
\text { Testing That } \\
\text { Prices Granger } \\
\text { Cause Polls }\end{array}$ \\
\hline Hadash-Taal & 39 & $7.102^{* * *}$ & 0.33 \\
Havoda & 46 & 1.066 & 0.9817 \\
IhudHayamin & 39 & $6.850^{* * *}$ & $5.820^{* * *}$ \\
Israel Beytenu & 43 & $4.162^{* *}$ & 1.85 \\
KaholLavan & 39 & 0.997 & 0.373 \\
Kulanu & 46 & $8.084^{* * *}$ & 1.251 \\
Likud & 38 & 0.568 & 1.148 \\
Meretz & 46 & 0.727 & 0.847 \\
Ra'am-Balad & 39 & $3.589^{* *}$ & 0.176 \\
Shas & 46 & 0.227 & 1.154 \\
HayminHachadash & 46 & $2.699^{*}$ & 0.096 \\
YehadutHaTorah & 46 & 0.189 & $5.922^{* * *}$ \\
Zehut & 37 & 0.464 & \\
\hline
\end{tabular}

Note: $* p<0.1,{ }^{* *} p<0.05,{ }^{* * *} p<0.01$. 
slightly more than the results from the causality tests applied to the whole population simultaneously.

For the finale, we provide in Table 5, the data that explain the title of this chapter. We compare the closeness of the market prices to the polls vis-à-vis their proximity to the official results of the elections.

From Table 5, it follows that the average absolute difference between the market and the polls was 0.79 , whereas the average absolute difference between the market and the official results was almost three times higher, 2.46. This result, together with the former evidence about the influence of the polls on the prediction market prices, raise the concern that the prediction market participants did not do much beyond imitating the polls. However, their work was not in vain since it had a positive marginal value as their accuracy was superior to that of the polls.

Table 5: Proximity of market prices to the polls and to the official results

\begin{tabular}{|c|c|c|c|c|c|}
\hline $\begin{array}{l}\text { Party Name } \\
\text { (Arranged by Size) }\end{array}$ & $\begin{array}{l}\text { Last } \\
\text { Trade } \\
\text { Price }\end{array}$ & $\begin{array}{l}\text { Last Polls } \\
\text { "Forecast" }\end{array}$ & $\begin{array}{l}\text { Official } \\
\text { (True) } \\
\text { Results }\end{array}$ & $\begin{array}{c}\text { Errors, } \\
\text { Predictions } \\
\text { Market }\end{array}$ & $\begin{array}{c}\text { Difference } \\
\text { between the } \\
\text { Predictions } \\
\text { and the Polls }\end{array}$ \\
\hline & & & & $\begin{array}{l}\text { Prices- } \\
\text { Official }\end{array}$ & Prices-Polls \\
\hline KacholLavan & 32.01 & 28 & 35 & -2.99 & 4.01 \\
\hline Likud & 29.33 & 28 & 35 & -5.67 & 1.33 \\
\hline Havoda & 9.75 & 11 & 6 & 3.75 & -1.25 \\
\hline YehadutHaTorah & 6.65 & 6 & 8 & -1.35 & 0.65 \\
\hline Hadash-Taal & 6.55 & 6 & 6 & 0.55 & 0.55 \\
\hline HayminHachadash & 6.39 & 6 & 0 & 6.39 & 0.39 \\
\hline IhudHayamin & 6.00 & 6 & 5 & 1.00 & 0.00 \\
\hline Meretz & 5.53 & 5 & 4 & 1.53 & 0.53 \\
\hline Shas & 5.49 & 5 & 8 & -2.51 & 0.49 \\
\hline Zehut & 5.10 & 6 & 0 & 5.10 & -0.90 \\
\hline Kulanu & 4.19 & 4 & 4 & 0.19 & 0.19 \\
\hline Israel Beytenu & 3.99 & 4 & 5 & -1.01 & -0.01 \\
\hline Raam-Balad & 3.99 & 4 & 4 & -0.01 & -0.01 \\
\hline
\end{tabular}




\section{Conclusions}

The prediction markets we studied had some flaws. It showed weak market inefficiency, and the prices determined in this market were heavily influenced by the polls, and for many parties we could conclude they were Granger caused by the polls. Moreover, the predictions were on average closer to the polls than to the election results. However, the predictions were more accurate on average than the polls, and this superior accuracy was notable for the parties that mattered (in the government formation). Since running this market costs very little compared to the millions of dollars spent on polls, and since it adds value, it seems that adding such a market to polls is worthwhile. As this chapter is based just on one elections campaign, we look forward to more papers that would study the interaction of polls and prediction markets and would shed more light on the merits of these markets in national political campaigns.

\section{References}

Arrow, K. J., Forsythe, R., Gorham, M., Hahn, R., Hanson, R., Ledyard, J. O., and Neumann, G. R. (2008). The promise of prediction markets. Science, 320, 877-878.

Atanasov, P., Rescober, P., Stone, E., Swift, S. A., Servan-Schreiber, E., Tetlock, P., and Mellers, B. (2016). Distilling the wisdom of crowds: Prediction markets vs. prediction polls. Management Science, 63(3), 691-706.

Berg, J., Forsythe, R., Nelson, F., and Rietz, T. (2008). Results from a dozen years of election futures markets research. Handbook of Experimental Economics Results, 1, 742-751.

Bickhchandani, S. D., Hirshleifer, D., and Welch, I. (1992). A theory of fads, fashion, custom, and cultural changes as informational cascades. Journal of Political Economy, 100, 992-1026.

Dana, J., Atanasov, P., Tetlock, P., and Mellers, B. (2019). Are markets more accurate than polls? The surprising informational value of "just asking". Judgment and Decision Making, 14 (2), 135-147.

Froot, K. A., Scharfstein, D., and Stein, J. C. (1992). Herd on the street: Informational inefficiencies in a market with short-term speculation. Journal of Finance, 47, 1461-1484. 
Hvide, H. K., Lee, J., and Odean, T. (2019). Easy money, cheap talk, or spuds: Inducing risk aversion in economics experiments. Working Paper, The Peder Sather Center for Advanced Study at UC Berkeley.

Schneider, T. (2019). A chronicle of non-reliability: How a gap of 36 mandates between the polls and the final election results was created. Globes, September 12(in Hebrew).

Shalita, C. (2019). Why they lied only to the polls of channel 12? Today it is clear. Globes, September 12(in Hebrew). 